\title{
Alkaloids from Tobacco Leaves: Isolation, Alkaloid Contents, and Potential Application as a Natural Pesticide against Bactrocera dorsalis
}

\begin{abstract}
Wenda Wang, ${ }^{\mathrm{a}}$ Jianhua Yao, ${ }^{\mathrm{b}}$ and Xiufang Cao ${ }^{\mathrm{a}, *}$
The essential oils from three different kinds of discarded tobacco leaves (flue-cured tobacco, burley tobacco, and sun-cured yellow tobacco) were extracted and isolated, and their isolation method, alkaloid contents, and potential application as a natural pesticide against Bactrocera dorsalis were investigated. The yields of the crude extracts were ranked as follows: sun-cured yellow tobacco was greater than flue-cured tobacco, which was greater than burley tobacco; all their alkaloid contents were analyzed via high performance liquid chromatography tandem mass spectrometry. The total contents of the 4 primary alkaloids (nicotine, anatabine, nornicotine, and anabasine) in the extracts were as follows: flue-cured tobacco $(62.1 \%)$ was greater than sun-cured yellow tobacco $(58.2 \%)$, which was greater than burley tobacco $(50.7 \%)$. The insecticidal activities of the extracts against Bactrocera dorsalis were evaluated via the stomach poisoning method, and the results indicated that sex had no considerable effect on the activity. Surprisingly, the activity of burley tobacco, which contained the lowest nicotine content, showed the best toxicity against Bactrocera dorsalis.
\end{abstract}

DOI: 10.15376/biores.17.1.1764-1780

Keywords: Discarded tobacco leaves; Alkaloid; Isolation; Analytical determination; Insecticidal activity; Bactrocera dorsalis

Contact information: a: College of Science, Huazhong Agricultural University, Wuhan 430070 China; b: China Tobacco Yunnan Industrial Co., Ltd., Kunming 650231 China;

*Corresponding author: caoxiufang@mail.hzau.edu.cn

\section{INTRODUCTION}

Tobacco is an important economic crop, as there are more than one billion smokers around the world. China has been the largest tobacco producer in the world for many years. In 2016, the total production of tobacco in China was approximately 2.1 million tons, of which more than $20 \%$ cannot be used to make cigarettes and was discarded (Zhang et al. 2012). Tobacco plants contain many valuable natural active substances, e.g., nicotine, which can be used to treat Alzheimer's disease and provide replacement therapy for the management of nicotine dependence. However, the discarded leaves do not currently have a reasonable method for consumption. The most common approach to deal with them is to either burn them or send them to a landfill, which is a waste of precious resources and generates pollution.

The oriental fruit fly, Bactrocera dorsalis (Hendel) is one of the most dangerous horticultural pests (Clarke et al. 2005). It attacks and destroys 250 different types of profitable fruits and vegetables on different continents of the world, especially in Africa and Asia. Up to now, out of all the efforts made to control the fruit fly population, using 
traditional pesticides is considered to be the best and most effective method. However, because of the increasing resistance to pesticides, negative impact on human health, and danger to natural ecosystems, the development of a new strategy to keep the pest population controlled is needed (Ant et al. 2012; Ali et al. 2017).

The use of plant extracts as insecticides dates back to the Roman period, and the efforts to obtain insecticides from plant extracts have not ceased (Balandrin et al. 1985; Scott et al. 2005; Kumar et al. 2013; Piton et al. 2014; Dogan et al. 2017; Kim et al. 2017). Compared to chemical insecticides, botanic insecticides are usually more easily degraded, more specific for pests, and more environmentally friendly. As early as the eighteenth century, people in France used tobacco and lime powder to control aphids.

The insecticidal substances in tobacco extract are primarily pyridine alkaloids. Nicotine is the major alkaloid in tobacco (Silva et al. 2013). Nornicotine, anatabine, and anabasine are the other common alkaloids found in tobacco (Armstrong et al. 1999). Currently, there are some quantitative methods for the determination of tobacco alkaloids, e.g., high-performance liquid chromatography (HPLC) (Saunders and Blume 1981; Sudan et al. 1984; Puripattanavong et al. 2013; Zammit et al. 2014), gas chromatography tandem mass spectrometry (GC-MS/MS) (Zagorevski and Loughmiller-Newman 2012; Xu et al. 2016), and high-performance liquid chromatography tandem mass spectrometry (HPLCMS/MS). (Xu et al. 2004; Li et al. 2015; Famele et al. 2017). High-performance liquid chromatography tandem mass spectrometry is considered to be a rapid, sensitive, and selective analytical technique for the determination of tobacco alkaloids and their metabolites (Yuan et al. 2013).

There are few studies on the use of tobacco extracts as insecticides. Most of these studies only focus on a single alkaloid, e.g., nicotine or anabasine (Puripattanavong et al. 2013; Zammit et al. 2014), and they do not pay attention to the impact of other alkaloids or mixed alkaloids on biological activity. Other studies just use the extract as an insecticide without composition analysis (Booker et al. 2010). As far as the authors know, there is currently no report on the simultaneous detection of multiple alkaloids and testing for insecticidal activity with the corresponding tobacco extracts. The understanding of the relationship between the alkaloid compositions and activity will allow elucidating the role of the minor alkaloids on the extracts.

In this work, the essential oils from three different kinds of discarded tobacco leaves were extracted and isolated, and their isolation method, alkaloid contents, and potential application as a natural pesticide against Bactrocera dorsalis were fully investigated. The process was simple, and the raw materials are readily available. Then, the authors established and validated a new HPLC-MS/MS method for simultaneously qualifying the four primary alkaloids (nicotine, anatabine, nornicotine, and anabasine) in the extracts. Finally, the potential insecticidal effects of the tobacco extracts on Bactrocera dorsalis after different time periods, and the effects of the sex and the type of extracts on the corrected mortality were fully investigated.

\section{EXPERIMENTAL}

\section{Plant and Insect Materials}

The flue-cured tobacco and burley tobacco came from the Enshi Tobacco Company in the Hubei province of China. The sun-cured yellow tobacco came from the Anhui Limited Liability Company tobacco industry in China. The flue-cured tobacco leaves were 
cut into pieces with scissors and baked at a temperature of $60{ }^{\circ} \mathrm{C}$ for $1 \mathrm{~h}$, then pulverized using an airflow mill FDV (Sumazaki Co., Ltd., Taiwan, China) to obtain a yellow-brown powder, which was packed in a refrigerator at a temperature of $4{ }^{\circ} \mathrm{C}$ later. The same method was applied to the burley tobacco and sun-cured yellow tobacco.

Bactrocera dorsalis adults were kept in $28 \mathrm{~cm} \times 28 \mathrm{~cm} \times 28 \mathrm{~cm}$ cages and provided with a constant supply of clean water and an artificial diet containing $7.5 \%$ sugar, $2.5 \%$ yeast extract, $0.5 \%$ agar, $2.5 \%$ honey, and $87 \%$ water (Li et al. 2011; Li et al. 2017). Adults and larvae were kept at a temperature of $28{ }^{\circ} \mathrm{C} \pm 1{ }^{\circ} \mathrm{C}$ with a relative humidity of $75 \% \pm$ $5 \%$ and on a $12 \mathrm{~h}$ light to $12 \mathrm{~h}$ dark photoperiod cycle for use.

\section{Chemical Reagents}

The methanol was chromatographic grade and purchased from Fisher Scientific (Hampton, NH). Water (18.2 M $\Omega$-cm) was produced by a Millipore Milli-Q system (Burlington, MA). Ammonium acetate was chromatographic grade and purchased from Fluka (Buchs, Switzerland). Formic acid was chromatographic grade and purchased from Shanghai Aladdin Biochemical Technology Co., Ltd. (Shanghai, China). The nicotine (99.7\%) came from the Dr. Ehrenstrofer GmbH reagent company (Augsburg, Germany). The anatabine $(97 \%)$, nornicotine $(98 \%)$, and anabasine $(94 \%)$ were purchased from J\&K (Beijing, China). The chloroform, anhydrous sodium sulphate, sodium hydroxide, sulphuric acid, and sucrose were analytical grade and purchased from Sinopharm Chemical Reagent Co., Ltd (Shanghai, China).

The four alkaloid (nicotine, anatabine, nornicotine, and anabasine) standards were diluted into $100 \mu \mathrm{g} / \mathrm{mL}$ stock solution with a $50 \%$ (v:v) methanol aqueous solution in four $100 \mathrm{~mL}$ brown flasks for the preparation of the standard solutions. The stock solution was stored in a refrigerator at a temperature of $4{ }^{\circ} \mathrm{C}$.

\section{Preparation of Tobacco Extracts}

First, $50 \mathrm{~g}$ of tobacco powder and $600 \mathrm{~mL}$ of tap water were added to a $1000 \mathrm{~mL}$ three-necked flask in a $60{ }^{\circ} \mathrm{C}$ constant water bath with mechanical stirring for $5 \mathrm{~h}$. Then, the mixture was centrifuged $\left(8000 \mathrm{r} / \mathrm{min}\right.$, at a temperature of $4{ }^{\circ} \mathrm{C}$ for $\left.15 \mathrm{~min}\right)$. The supernatant solution was collected and rendered alkaline with a saturated sodium hydroxide solution ( $\mathrm{pH}=13)$, followed by extraction with chloroform ( $300 \mathrm{~mL} 3$ times) for $30 \mathrm{~min}$ each time. The chloroform layers were combined and dried over anhydrous sodium sulfate overnight. Then, the chloroform solution was filtered and concentrated using a rotary vacuum evaporator (Shanghai Shensheng Technology Co., Ltd., Shanghai, China) at a temperature of $35^{\circ} \mathrm{C}$ to obtain the crude extract. Three kinds of tobacco extracts were all obtained with the above method. Multiple batches were repeated for each tobacco extract, and then mixed and stored at a temperature of $4{ }^{\circ} \mathrm{C}$.

The extract was diluted with a 50\% (v:v) methanol solution and filtered through a $0.22 \mu \mathrm{m}$ organic membrane filter (Tianjin Jin Teng experimental equipment Co., Ltd., Tianjin, China) to obtain a specified concentration of the sample solution in a $2 \mathrm{~mL}$ brown vial for HPLC-MS/MS analysis later.

\section{Instrument Analysis}

The alkaloid composition analyses were conducted using a LCMS-8050 (Shimadzu Corporation, Kyoto, Japan) device. The MS and HPLC parameters were optimized in order to achieve optimum sensitivity and accuracy. 
The chromatographic separation was carried out using a reversed-phase shim-pack XR-ODSIII column $(2.0 \mathrm{~mm} \times 75 \mathrm{~mm}, 1.6 \mu \mathrm{m})$ at a temperature of $35^{\circ} \mathrm{C}$. The mobile phase was composed of solvent $\mathrm{A}(0.1 \%$ formic acid and $10 \mathrm{mmol}$ of ammonium acetate in water) and solvent $\mathrm{B}$ (methanol) with a flow rate of $0.3 \mathrm{~mL} / \mathrm{min}$. The injection volume was $1 \mu \mathrm{L}$ and the run time was 10 min for each sample. Mobile phase elution gradient: 0 min, 100\% A, 100\%-95\%, 5 min; 95\%-80\%, 0.5 min; 80\%-100\%, 1.5 min; 100\%-100\%, $3 \mathrm{~min}$. The mass spectrometer was equipped with an electrospray ionization (ESI) source and was set in positive ionization mode with an interface temperature of $300{ }^{\circ} \mathrm{C}$ and an interface voltage of $4.5 \mathrm{kv}$. The nebulizing gas flow was $2.0 \mathrm{~L} / \mathrm{min}$, the drying gas flow was $10.0 \mathrm{~L} / \mathrm{min}$, and the heating gas flow was $10.0 \mathrm{~L} / \mathrm{min}$. The nebulizing gas, curtain gas, auxiliary gas, and collision gas were ultrapure argon. The dwell time was $100.0 \mathrm{~ms}$ for all four kinds of alkaloids.

\section{Content Determination of the Four Alkaloids}

The standard solutions of a series of concentrations containing four kinds of alkaloids were prepared using the stock solutions above. The concentrations of the four kinds of alkaloids in the standard solution were the same. Considering that the concentration of nicotine in the actual sample was much higher than the concentrations of the other three alkaloids, the highest concentration of nicotine was set higher in the calibration standard. The concentrations of nicotine were set as $0.01 \mu \mathrm{g} / \mathrm{mL}, 0.1 \mu \mathrm{g} / \mathrm{mL}$, $0.5 \mu \mathrm{g} / \mathrm{mL}, 1 \mu \mathrm{g} / \mathrm{mL}, 5 \mu \mathrm{g} / \mathrm{mL}, 10 \mu \mathrm{g} / \mathrm{mL}$, and $20 \mu \mathrm{g} / \mathrm{mL}$, while the other three alkaloids were set as $0.01 \mu \mathrm{g} / \mathrm{mL}, 0.1 \mu \mathrm{g} / \mathrm{mL}, 0.5 \mu \mathrm{g} / \mathrm{mL}$, and $1,5 \mu \mathrm{g} / \mathrm{mL}$. The calibration curves of the four kinds of alkaloids were drawn, and the linear regression equations were obtained. All coefficients of determination were greater than 0.997. The peak areas of the analytes and the data handling were computed using the Lab Solutions software (version 5.80, Shimadzu Corporation, Kyoto, Japan).

\section{Preliminary Experiment of Bactrocera Dorsalis Sex and Test Concentration}

The activity of the alkaloids was evaluated via the stomach poisoning method, as follows: the sun-cured yellow tobacco extract was dissolved in acetone and diluted with a sucrose aqueous solution (w:v ratio of 1 to 10 ) to a concentration of $0.125,0.250,0.500$, 1.000 , and $2.000 \mathrm{mg} / \mathrm{mL}$. The solutions were uniformly added into a flat round absorbent cotton $(3 \mathrm{~g} \pm 0.1 \mathrm{~g})$ and tiled the cotton on the bottom of a $250 \mathrm{~mL}$ Erlenmeyer flask and then sealed the flask neck with a single layer of white gauze. The food and water were removed from the cage where the Bactrocera dorsalis were fed. After $6 \mathrm{~h}$, the Bactrocera dorsalis which had emerged approximately 4 weeks to 5 weeks ago were separated into a male group and a female group. Then, 20 test insects (10 male and 10 female) were added to the flask described above. A control group was treated in the same way but without using any tobacco extract. The mortality of the male and female subjects was counted after $24 \mathrm{~h}$, and the mortality or corrected mortality was calculated using the following formula, as shown in Eqs. 1 and 2, respectively,

$$
\begin{aligned}
& \text { Mortality }=\frac{\text { Number of dead insects }}{\text { Number of introduced insects }} \times 100 \\
& \text { Corrected Mortality }=\frac{\text { OMT }- \text { OMC }}{100-\text { control mortality }} \times 100
\end{aligned}
$$

where OMT represents the observed mortality in treatment, OMC represents the observed mortality in control (each experiment was performed in triplicate). 


\section{Insecticidal Activity of the Three Kinds of Tobacco Extracts}

In order to study the insecticidal activity of the different kinds of tobacco extracts, solutions at concentrations of $0.250,0.500$, and $1.000 \mathrm{mg} / \mathrm{mL}$ were tested using the stomach poisoning method on Bactrocera dorsalis, which had emerged approximately 4 weeks to 5 weeks earlier. The corrected mortality of the male and female subjects was counted after 24, 48, and $72 \mathrm{~h}$. Imidacloprid was selected as the positive control with a series concentration of $3.9,7.8,15.6,31.2,62.5,125$, and $250 \mu \mathrm{g} / \mathrm{mL}$. The experimental method was the same as the above section. Insects from the cage were randomly grabbed, and the sex was never distinguished.

\section{Insecticidal Activity of the Flue-Cured Tobacco Extract on Bactrocera Dorsalis from Different Time Periods}

The authors studied the insecticidal activity of tobacco extract on Bactrocera dorsalis at different time periods, i.e., 1 week to 5 weeks. Based on the screening results, the flue-cured tobacco extract was selected as the tested extract, the concentrations were further adjusted to $0.2,0.4,0.6,0.8,1.0,1.2$, and $1.4 \mathrm{mg} / \mathrm{mL}$. The insecticidal activity after $24 \mathrm{~h}, 48 \mathrm{~h}$, and $72 \mathrm{~h}$ was studied, and the corresponding mortality and corrected mortality values were calculated (as shown in Eqs. 1 and 2, respectively).

\section{RESULTS AND DISCUSSION}

\section{Yield of the Three Tobacco Crude Extracts}

The weights of the crude extracts are shown in Fig. 1. The result was expressed as the weight ( $\mathrm{g}$ ) of crude extract per $100 \mathrm{~g}$ of tobacco leaves. The three kinds of tobacco leaves were pretreated and extracted in the same way. According to Fig.1, the highest extraction amount was sun-cured tobacco, followed by flue-cured tobacco, and the lowest was burley tobacco. The standard deviations order of the three repeats were as follows: sun-cured yellow tobacco $(0.127 \mathrm{~g})>$ flue-cured tobacco $(0.116 \mathrm{~g})>$ burley tobacco $(0.049$ g).

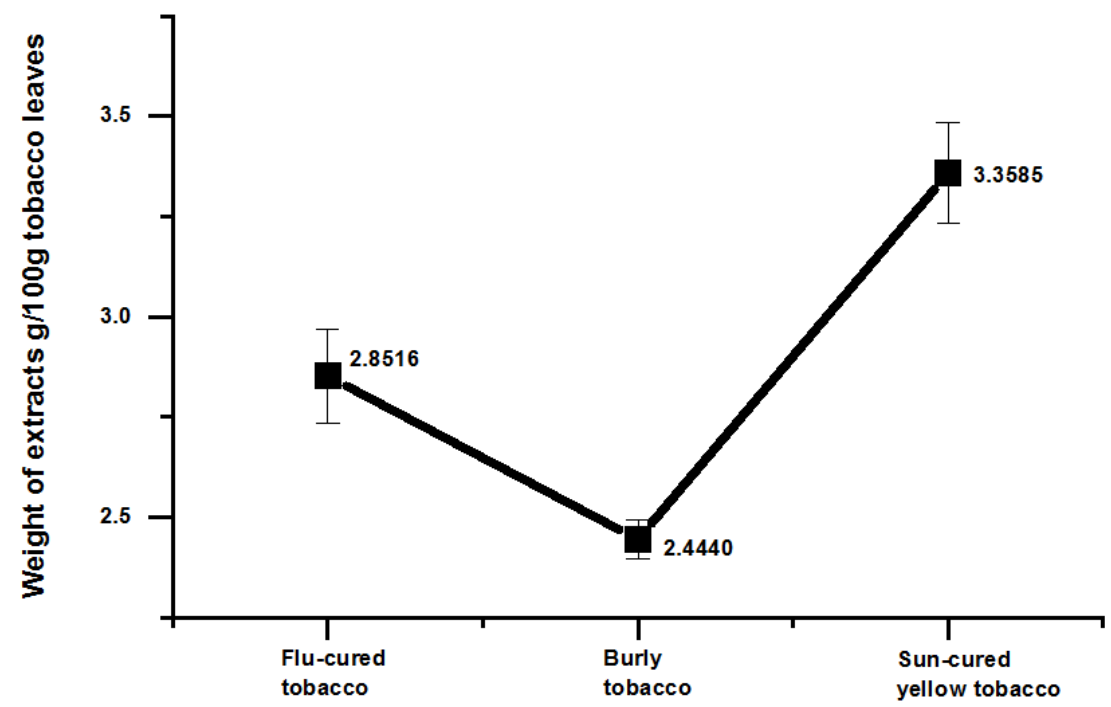

Fig. 1. The crude extract yield from different tobacco leaves (Note: the data in Fig. 1 is the average of three successive repeated extractions) 
The burley tobacco extract was a reddish-brown transparent liquid, while the suncured yellow tobacco extract was a dark brown viscous liquid. The color of the flue-cured tobacco extract was between the other two. The three extracts had a surprisingly strong irritating smell.

In tobacco leaves, the alkaloids are primarily found as salts of organic acids, e.g., citrate and malate. The salts can dissolve in water. Tobacco alkaloids are weak bases and soluble in chloroform. In the presence of a strong alkali (a pH greater than or equal to 10), most of the salt solution will produce free alkaloids, which can be extracted with an organic solution, e.g., chloroform. (Hu et al. 2015). Finally, the alkaloid-rich tobacco extracts were obtained after drying and concentrating.

\section{Optimization of the Instrument Parameters and Method Verification}

The full identification of the analytes was achieved by using the multiple reactions monitoring (MRM) mode with one precursor ion and two product ions. The precursor ions were determined via a Q1 full scan using a syringe pump for $0.1 \mu \mathrm{g} / \mathrm{mL}$ of continuous mixing standards. Under the positive ion mode, the most abundant ions in the Q1 scan mass spectra were $[\mathrm{M}+\mathrm{H}]^{+}$for all the analytes. The precursor ions selected in the quadrupole Q1 were further fragmented and the product ions were registered by scanning the quadrupole Q3. The collision energy and the Q1, Q3 potentials were adjusted in MRM mode for each transition monitored to reach the highest sensitivity for all the analytes (as shown in Table 1). The most intense product ion was used for quantification, while the second most intense was used to complete the identification (Famele et al. 2017). The ion flow diagrams of four alkaloids nicotinine, anatabine, nornicotinine, and anabasine obtained by the above method and the ion flow diagram of a single alkaloid are shown in Fig. 2.

Table 1. Optimization of the Mass Spectrometry Parameters

\begin{tabular}{|c|c|c|c|c|c|}
\hline \multirow{2}{*}{ Compound } & $\begin{array}{c}\text { Precursor lon } \\
(\mathrm{m} / \mathrm{z})\end{array}$ & $\begin{array}{c}\text { Product lons } \\
(\mathrm{m} / \mathrm{z})\end{array}$ & $\begin{array}{c}\text { Q1 Pre-Bias } \\
(\mathrm{V})\end{array}$ & $\begin{array}{c}\mathrm{CE} \\
(\mathrm{V})\end{array}$ & $\begin{array}{c}\text { Q3 Pre-Bias } \\
(\mathrm{V})\end{array}$ \\
\hline \multirow{2}{*}{ Nicotine } & \multirow{2}{*}{163.10} & $130.10^{*}$ & -10.0 & -21.0 & -14.0 \\
\cline { 3 - 6 } & \multirow{2}{*}{ Anatabine } & 132.10 & -10.0 & -19.0 & -26.0 \\
\hline \multirow{2}{*}{ Nornicotine } & \multirow{2}{*}{161.00} & $144.10^{*}$ & -10.0 & -15.0 & -16.0 \\
\cline { 3 - 6 } & \multirow{2}{*}{ Anabasine } & 107.10 & -10.0 & -14.0 & -26.0 \\
\cline { 2 - 6 } & \multirow{2}{*}{163.10} & $130.10^{*}$ & -10.0 & -17.0 & -27.0 \\
\cline { 2 - 6 } & 132.05 & -10.0 & -20.0 & -26.0 \\
\cline { 2 - 6 } & $146.10^{*}$ & -10.0 & -19.0 & -16.0 \\
\hline
\end{tabular}

Note: ${ }^{*}$ is a quantitative product ion

After the solution was eluted and the mass spectral parameters were optimized, the samples were added to the sample chamber at a temperature of $4{ }^{\circ} \mathrm{C}$ in the dark and were analyzed via HPLC-MS/MS. The limit of detection (LOD) and limit of quantification (LOQ) were estimated by diluting the standard solutions to concentrations with signal-tonoise ratios of approximately 3 and approximately 10, respectively (as shown in Table 2). It can be seen from Table 2 that the determination accuracy of four primary alkaloids (LOD, LOQ) with the LCMS method in this paper were as follows: nicotine $(5.59 \mathrm{ng} / \mathrm{mL}, 18.65$ $\mathrm{ng} / \mathrm{mL})$; anatabine $(2.91 \mathrm{ng} / \mathrm{mL}, 9.71 \mathrm{ng} / \mathrm{mL})$; nornicotine $(2.26 \mathrm{ng} / \mathrm{mL}, 7.53 \mathrm{ng} / \mathrm{mL})$; and anabasine $(1.02 \mathrm{ng} / \mathrm{mL}, 3.41 \mathrm{ng} / \mathrm{mL})$. The LOD and LOQ of the four alkaloids were within $10 \mathrm{ng} / \mathrm{mL}$ (except for the LOQ of nicotine, which was $18.65 \mathrm{ng} / \mathrm{mL}$ ). The sensitivity was 
comparable to that found by Famele et al. (2017) but was much lower than the values found by $\mathrm{Xu}$ et al. (2004) and Weymarn et al. (2016), which was considerably higher than the values found by Li et al. 2015). The sensitivity of the method was sufficient to measure the actual tobacco samples, because the nicotine content was between 1 and $10 \mu \mathrm{g} / \mathrm{mL}$, and the other three alkaloid contents were between 0.01 and $1 \mu \mathrm{g} / \mathrm{mL}$. The injection time was chosen for $10 \mathrm{~min}$ in order to leave enough time to clean the column residue and balance the baseline.
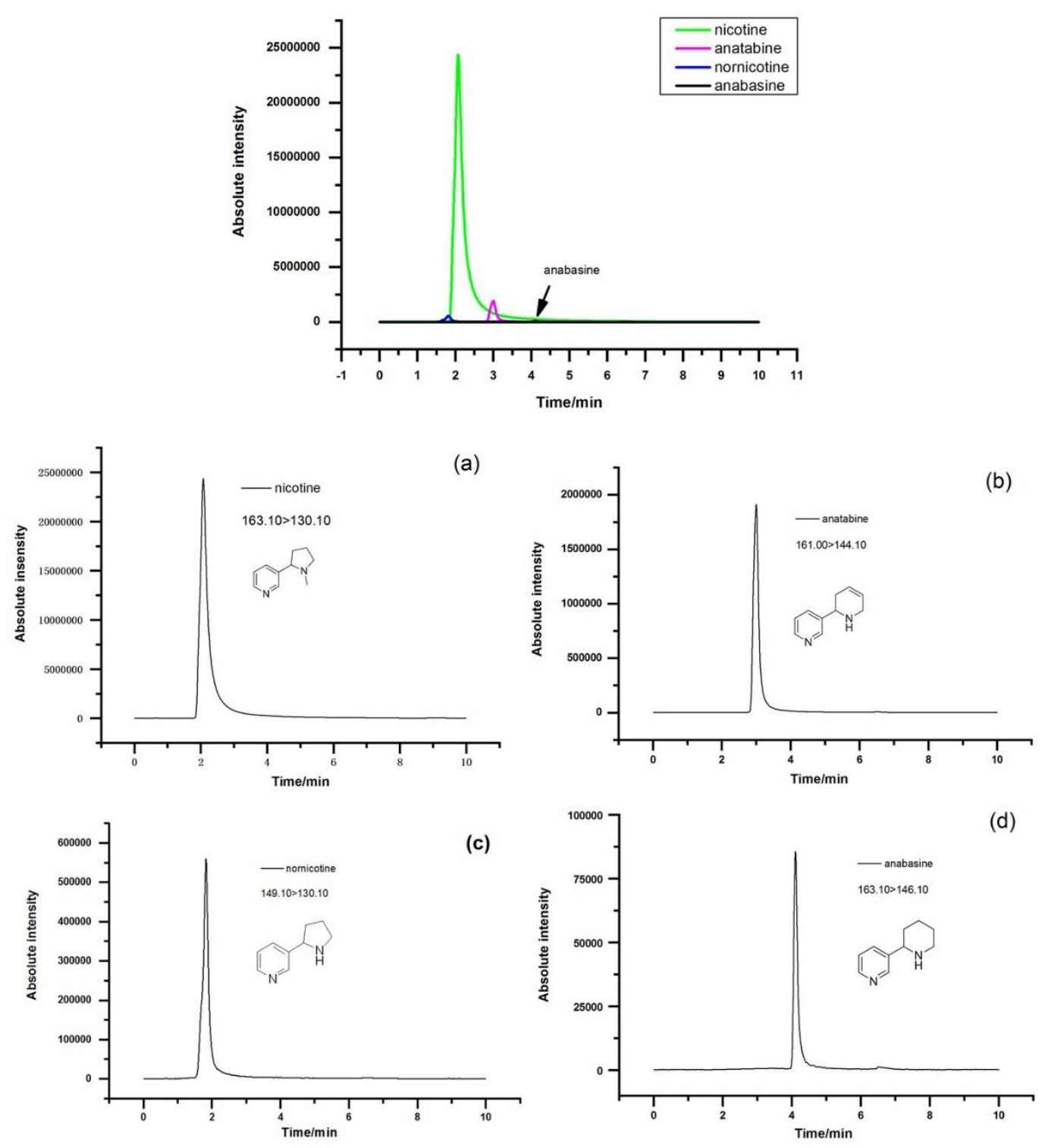

Fig. 2. Selective ion chromatograms of the four alkaloids (XIC): (a) nicotine; (b) anatabine; (c) nornicotine; (d) anabasine

In order to investigate the stability of the method, the authors determined the intraday and the inter-day relative standard deviations with the same control sample (a mix of the tobacco samples). Six replicates were prepared for each concentration and the samples were analyzed over 3 consecutive days. The results were expressed as the relative standard 
deviation (RSD) and are shown in Table 2. It can be seen from Table 2 that the intra-day RSDs (less than 1\%) were obviously smaller than the inter-day RSDs (less than 10\%). As such, it can be seen that the instrument had good reproducibility, especially for the intraday testing.

Table 2. Regression Curve, Accuracy, Precision, and LOD and LOQ of the Established Method

\begin{tabular}{|c|c|c|c|c|c|c|c|}
\hline Compound & tR/min & Regression curve & $R^{2}$ & $\begin{array}{c}\text { Intra- } \\
\text { day } \\
\text { RSD } \\
(\%)\end{array}$ & $\begin{array}{c}\text { Inter- } \\
\text { day } \\
\text { RSD } \\
(\%)\end{array}$ & $\begin{array}{c}\mathrm{LOD} \\
(\mathrm{ng} / \mathrm{mL})\end{array}$ & $\begin{array}{c}\mathrm{LOQ} \\
(\mathrm{ng} / \mathrm{mL})\end{array}$ \\
\hline Nornicotine & 1.829 & $\mathrm{f}(\mathrm{x})=1.49321 \mathrm{e}^{\wedge} 7^{\star} \mathrm{x}+1.03915 \mathrm{e}^{\wedge} 6$ & 0.9986 & 0.99 & 9.86 & 2.26 & 7.53 \\
\hline Nicotine & 2.082 & $\mathrm{f}(\mathrm{x})=1.96943 \mathrm{e}^{\wedge} 7^{*} \mathrm{x}+3.82776 \mathrm{e}^{\wedge} 6$ & 0.9970 & 0.83 & 5.44 & 5.59 & 18.65 \\
\hline Anatabine & 2.991 & $\mathrm{f}(\mathrm{x})=2.02233 \mathrm{e}^{\wedge} 7^{\star} \mathrm{x}+868805$ & 0.9994 & 0.88 & 3.80 & 2.91 & 9.71 \\
\hline Anabasine & 4.061 & $\mathrm{f}(\mathrm{x})=4.90866 \mathrm{e}^{\wedge} 6^{*} \mathrm{x}+392300$ & 0.9982 & 0.70 & 9.50 & 1.02 & 3.41 \\
\hline
\end{tabular}

The recovery of the control sample was measured. Based on the results of the previous control samples, samples of the $100 \mu \mathrm{g} / \mathrm{mL}$ stock solutions of the four alkaloids were added. The results are shown in Table 3 . The percentage of recovery of four alkaloids ranged from $82.43 \%$ to $116.05 \%$. The data showed that the method established in this experiment had sufficient stability and reliability, which can ensure the quantitative determination of the four alkaloids in the sample.

Table 3. Recovery of the Controlled Sample

\begin{tabular}{|c|c|c|c|c|}
\hline Compound & \multirow{2}{*}{ Initial } & Added & Found & Recovery (\%) \\
\hline Nicotine & 8.331 & 8.189 & 16.165 & 95.66 \\
\hline \multirow{3}{*}{ Anatabine } & \multirow{3}{*}{0.406} & 0.376 & 0.743 & 89.74 \\
\cline { 3 - 5 } & & 0.751 & 1.025 & 82.43 \\
\cline { 3 - 5 } & \multirow{3}{*}{0.135} & 1.502 & 1.674 & 84.43 \\
\cline { 3 - 5 } & & 0.076 & 0.208 & 96.17 \\
\cline { 3 - 5 } & & 0.152 & 0.292 & 103.51 \\
\cline { 3 - 5 } & \multirow{3}{*}{ Nornicotine } & 0.304 & 0.479 & 113.29 \\
\cline { 3 - 5 } & \multirow{3}{*}{ Anabasine } & 0.058 & 0.163 & 105.37 \\
\cline { 3 - 5 } & & 0.116 & 0.228 & 108.58 \\
\cline { 3 - 5 } & & 0.232 & 0.371 & 116.05 \\
\hline
\end{tabular}

\section{Content Data}

Through the method established in the above section, this study determined the contents of the four kinds of alkaloids in three actual samples, i.e., flue-cured tobacco, burley tobacco, and sun-cured yellow tobacco. The results were expressed as the weight of alkaloid in the extract. The samples were analyzed three times in succession and the results were the average value of three replications (as shown in Figs. 3 and 4). It can be seen from Fig. 3 that the content of the three kinds of minor alkaloids was low. Generally, the content of total alkaloids in flue-cured tobacco was the highest, but burley tobacco had the highest 
content of small alkaloids, especially nornicotine. The nicotine content in the sun-cured yellow tobacco was slightly lower than the flue-cured tobacco, but the yield of the crude extract was obviously higher than the yield of the other two kinds of tobacco. Taking the yield and alkaloid content into consideration, the sun-cured yellow tobacco deserves more attention in terms of its further utilization. However, it is important to keep in mind that the relative differences were small in the present experiments, so similar results were obtained for the three classes of tobacco.

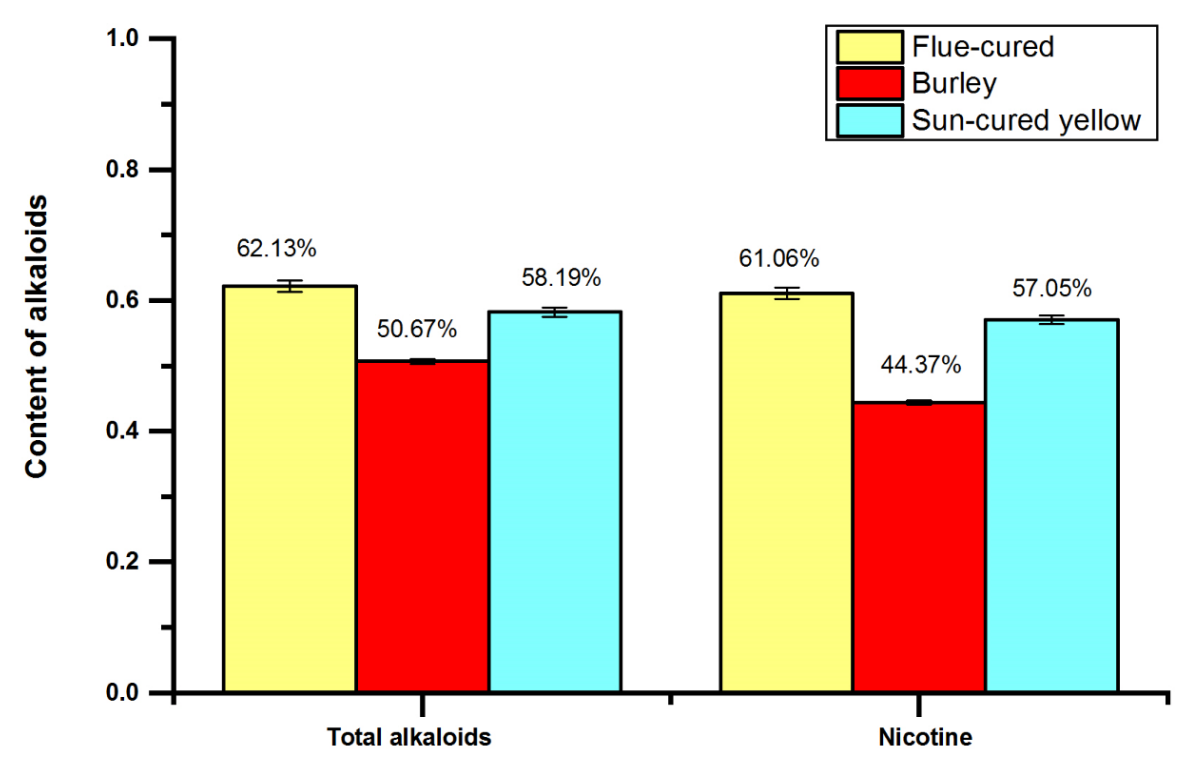

Fig. 3. Total alkaloids and nicotine content of the three kinds of tobacco

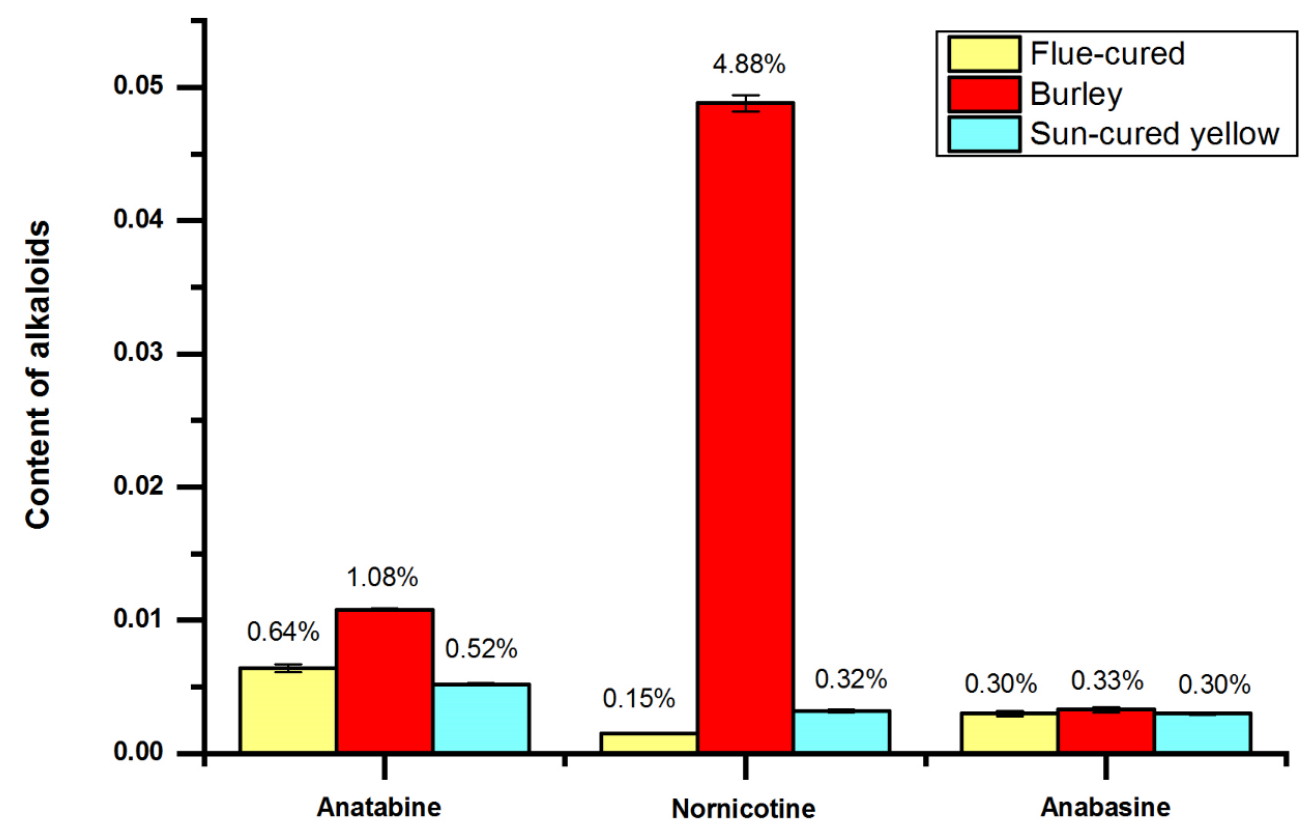

Fig. 4. Contents of the three kinds of minor alkaloids in the three kinds of tobacco 


\section{Effects of Sex on the Mortality of Bactrocera dorsalis}

In order to test the insecticidal activity of tobacco extracts against Bactrocera dorsalis (adults 4 weeks old to 5 weeks old), this study examined both the gender and concentration settings in the pre-experiment. Based on the previously determined content of the extract, sun-cured yellow tobacco was selected as the test extract. The death of the test insects after the $24 \mathrm{~h}$ administration is shown in Fig. 5. Generally speaking, the mortality rates of the male and female insects were similar or showed small differences under the same tested concentration. Specifically, at the concentration of $0.125 \mathrm{mg} / \mathrm{mL}$, the male mortality rate was $10 \%$, while the female mortality rate was $6.67 \%$. The male mortality rate was $13.33 \%$ at $0.250 \mathrm{mg} / \mathrm{mL}$, while the female mortality rate was $5.00 \%$. The male mortality rate was $18.33 \%$ at $0.500 \mathrm{mg} / \mathrm{mL}$, while the female mortality rate was $23.33 \%$. The male mortality rate was $43.33 \%$ at $1.000 \mathrm{mg} / \mathrm{mL}$, while the female was mortality rate $45.00 \%$. The male mortality rate was $48.33 \%$ at $2.000 \mathrm{mg} / \mathrm{mL}$, while the female mortality rate was $46.67 \%$. The effects of sex on the mortality were analyzed using the LSD method using SPSS software. As shown in Table 4, the gender-specific significance was 0.914 , which indicated that sex had no significant effect on the mortality rate. Therefore, it was not necessary to separate the males and the females in the experiments. Effective concentrations should be approximately $0.25 \mathrm{mg} / \mathrm{mL}$ to $1.0 \mathrm{mg} / \mathrm{mL}$.

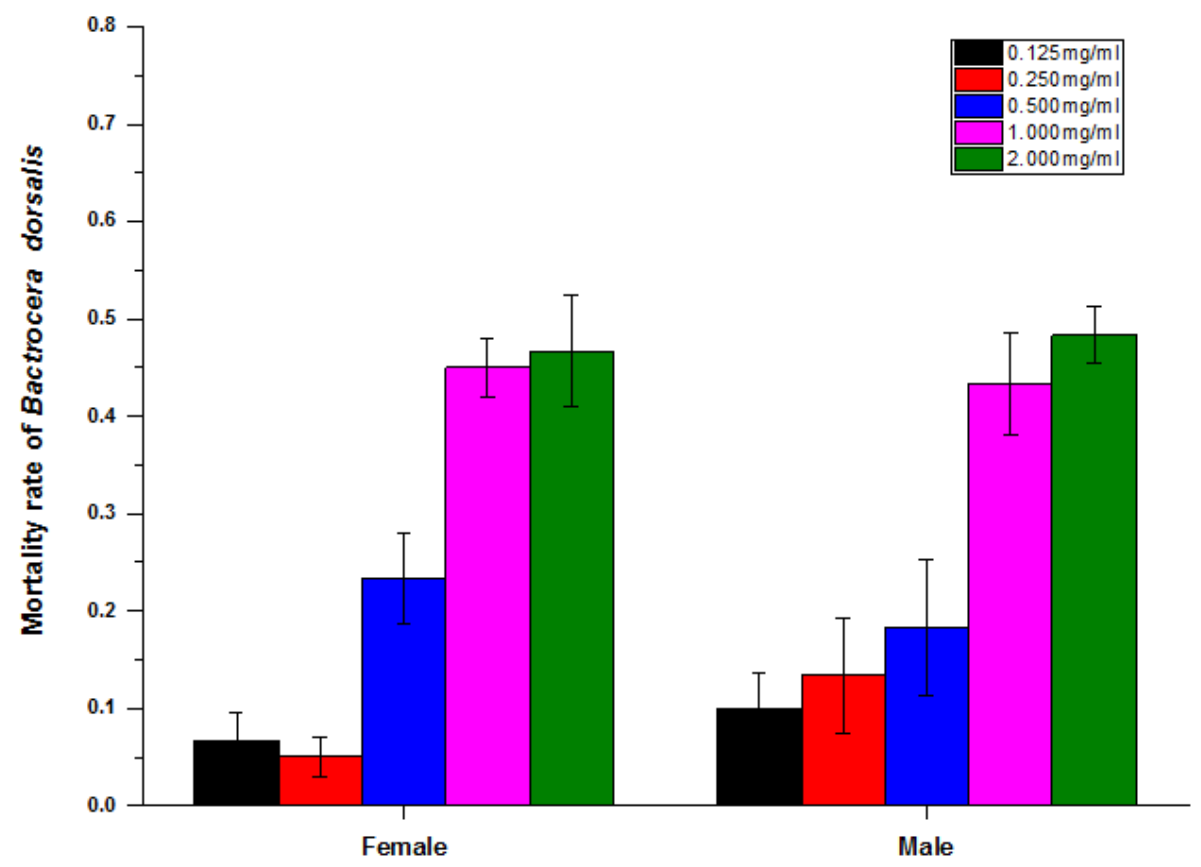

Fig. 5. Mortality rate of the male and female individuals of Bactrocera dorsalis at different concentrations of sun-cured yellow tobacco extract (Note: the mortality rates are the average of three repeated experiments) 
Table 4. Parameter Estimates for the Effect of Gender on the Mortality of Bactrocera dorsalis

\begin{tabular}{|c|c|c|c|c|c|c|}
\hline \multicolumn{2}{|l|}{ Dependent-variable: Mortality } \\
\hline Parameters & B & \multirow{2}{*}{ Standard Error } & $\mathrm{t}$ & \multirow{2}{*}{ Sig. } & \multicolumn{2}{|c|}{$95 \%$ Confidence Interval for Mean } \\
\cline { 5 - 7 } & & & & & Lower Bound & Upper Bound \\
\hline Intercept & 26.664 & 8.485 & 3.142 & .014 & 7.097 & 46.231 \\
\hline [sex=female] & -1.330 & 12.000 & -.111 & .914 & -29.002 & 26.342 \\
\hline [sex=male] & $0^{\text {a }}$ & - & - & - & - & - \\
\hline
\end{tabular}

Note: a - this parameter is set to zero because it is redundant

\section{Effects of the Extract Species on the Mortality of Bactrocera dorsalis}

After the preliminary elimination of sexual dependence on mortality and the determination of the effective insecticidal concentration of the extract, the authors examined the effects of the three different kinds of tobacco on the insecticidal activity (4 weeks old to 5 weeks old adults were chosen as the test insect), whose results are shown in Fig. 6.

Burley tobacco showed the best insecticidal activity after $24 \mathrm{~h}$. According to the above alkaloid content determination results, the nicotine content of burley tobacco was the lowest (44.4\%); however, its three kinds of minor alkaloid contents were higher than the other two tobaccos. In addition, the three minor alkaloids contents of flue-cured tobacco and sun-cured yellow tobacco were almost the same, while the nicotine contents were different; flue-cured tobacco (61.1\%) was greater than sun-cured yellow tobacco $(57.0 \%)$, and the bioactivity of flue-cured tobacco was slightly higher than the bioactivity of suncured yellow tobacco. As such, the authors believe that the higher bioactivity of burley tobacco after $24 \mathrm{~h}$ compared to flue-cured tobacco and sun-cured yellow tobacco was due to the increase in the minor alkaloid content, and the bioactivity of the minor alkaloids was much greater than the bioactivity of nicotine at the same weight. However, this change can only be reflected in a short time, as it was seen that after 48 and $72 \mathrm{~h}$, the bioactivity of burley tobacco slowly increased and could not match the other two kinds of tobacco.

In summary, it is believed that the minor alkaloids showed better bioactivity compared to nicotine during a short time period, which may be due to the multiple modes of action of the minor alkaloids. The tested concentrations of imidacloprid (positive control) were $3.9,7.8,15.6,31.2,62.5,125$, and $250 \mu \mathrm{g} / \mathrm{mL}$, and the corresponding corrected mortality rates were $20.0 \%, 40.0 \%, 72.5 \%, 83.3 \%, 86.3 \%, 93.3 \%$, and $96.7 \%$. The $\mathrm{LC}_{50}$ of the imidacloprid was $11.94 \mu \mathrm{g} / \mathrm{mL}(24 \mathrm{~h})$. Although there is still a large gap in activity between active extracts and the chemical insecticide, tobacco extracts provide a good choice as a promising alternative for its special advantages. 


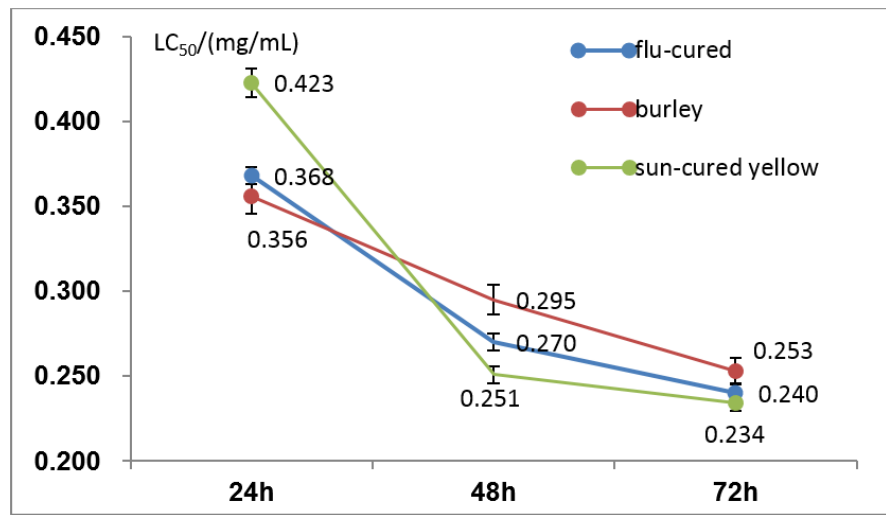

Fig. 6. Insecticidal activity of the different tobacco extracts against Bactrocera dorsalis

\section{Effects of Flue-cured Tobacco Extract on the Mortality of Bactrocera dorsalis in Different Time Periods}

After confirming the insecticidal activity of the different extracts, the authors selected flue-cured tobacco extract to test the insecticidal activity on Bactrocera dorsalis at different time periods after emergence, i.e., first week, second week, third week, fourth week, and fifth week. The flue-cured tobacco concentrations were further adjusted to 0.2 , $0.4,0.6,0.8,1.0,1.2$, and $1.4 \mathrm{mg} / \mathrm{mL}$, and the results are shown in Table 5.

Table 5. Flue-cured Tobacco Extracts' Insecticidal Activity of Bactrocera dorsalis in Different Periods

\begin{tabular}{|c|c|c|c|c|c|c|c|c|}
\hline Week & Time & $0.2 \mathrm{mg} / \mathrm{L}$ & $0.4 \mathrm{mg} / \mathrm{L}$ & $0.6 \mathrm{mg} / \mathrm{L}$ & $0.8 \mathrm{mg} / \mathrm{L}$ & $1.0 \mathrm{mg} / \mathrm{L}$ & $1.2 \mathrm{mg} / \mathrm{L}$ & $1.4 \mathrm{mg} / \mathrm{L}$ \\
\hline \multirow{3}{*}{1} & $24 \mathrm{~h}$ & $16.2 \pm 2.96$ & $17.9 \pm 5.13$ & $33.3 \pm 5.12$ & $57.3 \pm 7.83$ & $62.4 \pm 18.01$ & $74.4 \pm 5.13$ & $84.6 \pm 5.12$ \\
\hline & $48 \mathrm{~h}$ & $23.8 \pm 8.73$ & $39.0 \pm 11.90$ & $58.1 \pm 6.59$ & $75.2 \pm 8.73$ & $82.9 \pm 5.71$ & $94.3 \pm 0.00$ & 100 \\
\hline & $72 \mathrm{~h}$ & $39.2 \pm 8.99$ & $54.9 \pm 12.24$ & $60.8 \pm 3.40$ & $84.3 \pm 3.40$ & $92.2 \pm 3.39$ & $96.1 \pm 3.39$ & 100 \\
\hline \multirow{3}{*}{2} & $24 \mathrm{~h}$ & $0 \pm 5.26$ & $15.8 \pm 5.26$ & $21.1 \pm 0.00$ & $35.1 \pm 6.08$ & $42.1 \pm 7.45$ & $66.7 \pm 18.5$ & $70.2 \pm 19.93$ \\
\hline & $48 \mathrm{~h}$ & $0 \pm 6.19$ & $25.0 \pm 9.28$ & $54.4 \pm 26.52$ & $57.1 \pm 5.36$ & $69.6 \pm 20.29$ & $89.3 \pm 7.58$ & $89.3 \pm 0.00$ \\
\hline & $72 \mathrm{~h}$ & $3.51 \pm 10.72$ & $41.1 \pm 14.18$ & $65.2 \pm 11.36$ & $73.2 \pm 10.72$ & $89.3 \pm 5.36$ & $98.2 \pm 3.09$ & $98.2 \pm 3.09$ \\
\hline \multirow{3}{*}{3} & $24 \mathrm{~h}$ & $1.8 \pm 3.04$ & $35.1 \pm 21.27$ & $43.9 \pm 10.96$ & $86.8 \pm 3.72$ & $89.5 \pm 0.00$ & $94.7 \pm 9.11$ & $98.2 \pm 3.03$ \\
\hline & $48 \mathrm{~h}$ & $9.6 \pm 14.52$ & $65.4 \pm 11.53$ & $67.3 \pm 6.66$ & $92.3 \pm 3.32$ & $97.1 \pm 4.08$ & 100 & 100 \\
\hline & $72 \mathrm{~h}$ & $19.6 \pm 12.25$ & $73.5 \pm 12.47$ & $76.5 \pm 0.00$ & $96.1 \pm 3.39$ & $97.1 \pm 4.16$ & 100 & 100 \\
\hline \multirow{3}{*}{4} & $24 \mathrm{~h}$ & $12.8 \pm 5.13$ & $35.0 \pm 7.83$ & $52.1 \pm 10.67$ & $79.5 \pm 8.88$ & $81.2 \pm 14.8$ & $94.9 \pm 0.00$ & $98.3 \pm 2.96$ \\
\hline & $48 \mathrm{~h}$ & $31.5 \pm 3.20$ & $57.4 \pm 13.98$ & $66.7 \pm 5.55$ & $92.6 \pm 3.30$ & $94.4 \pm 0.00$ & $98.1 \pm 3.21$ & 100 \\
\hline & $72 \mathrm{~h}$ & $35.8 \pm 3.26$ & $64.1 \pm 19.89$ & $71.7 \pm 5.66$ & $98.1 \pm 3.27$ & $98.1 \pm 3.27$ & 100 & 100 \\
\hline \multirow{3}{*}{5} & $24 \mathrm{~h}$ & $3.5 \pm 10.96$ & $15.8 \pm 10.53$ & $45.6 \pm 6.07$ & $64.9 \pm 6.08$ & $73.7 \pm 5.26$ & $89.5 \pm 5.26$ & $96.5 \pm 6.08$ \\
\hline & $48 \mathrm{~h}$ & $10.9 \pm 16.66$ & $32.7 \pm 8.33$ & $58.2 \pm 6.29$ & $87.3 \pm 8.32$ & $89.1 \pm 0.00$ & 100 & 100 \\
\hline & $72 \mathrm{~h}$ & $14.8 \pm 11.56$ & $44.4 \pm 16.66$ & $72.2 \pm 0.00$ & $94.4 \pm 5.56$ & $94.4 \pm 0.00$ & 100 & 100 \\
\hline
\end{tabular}

Wang et al. (2022). "Tobacco alkaloids as a pesticide," BioResources 17(1), 1764-1780. 1775 
The $\mathrm{LC}_{50}$ of the flue-cured tobacco extract at 24, 48, and $72 \mathrm{~h}$ was tested and calculated. As it is known that the larger the LC50 value, the better the vitality of Bactrocera dorsalis. As shown in Fig. 7, there were differences in the resistance of Bactrocera dorsalis at different time periods. The order of the vitality of the Bactrocera dorsalis at the different time periods were as follows: the second week $>$ the fifth week $>$ the first week $>$ the third week $>$ the fourth week (except for $24 \mathrm{~h}$, in which the fifth week was less than the first week). The activity of Bactrocera dorsalis was the strongest at the second week. Bactrocera dorsalis usually starts to mate and breed between two weeks to three weeks after emergence. Mating and breeding, as well as fights between individuals, will consume a lot of energy, which may have led to the decline in vitality. From the beginning of the third week, the activity continuously declined for two consecutive weeks. Bactrocera dorsalis adults can mate multiple times during their lifetime. The activity started to rebound on the fifth week, which could mean the arrival of the next breeding cycle. This activity data can guide us in the control of Bactrocera dorsalis by adding to the dosage when the vitality of Bactrocera dorsalis is better. The increased dosage before the outbreak period not only can kill the pest itself, but it also can kill male and female individuals that are about to mate and breed. The second week was undoubtedly key to controlling the number of Bactrocera dorsalis. In addition, the fifth week, when facing the rebound of the vitality of the pests, is another critical time point to increase the amount of insecticide. Two critical time points were separated by approximately 3 weeks under laboratory suitable culture conditions. When in the wild environment, it can be predicted that the breeding cycle would be properly extended.

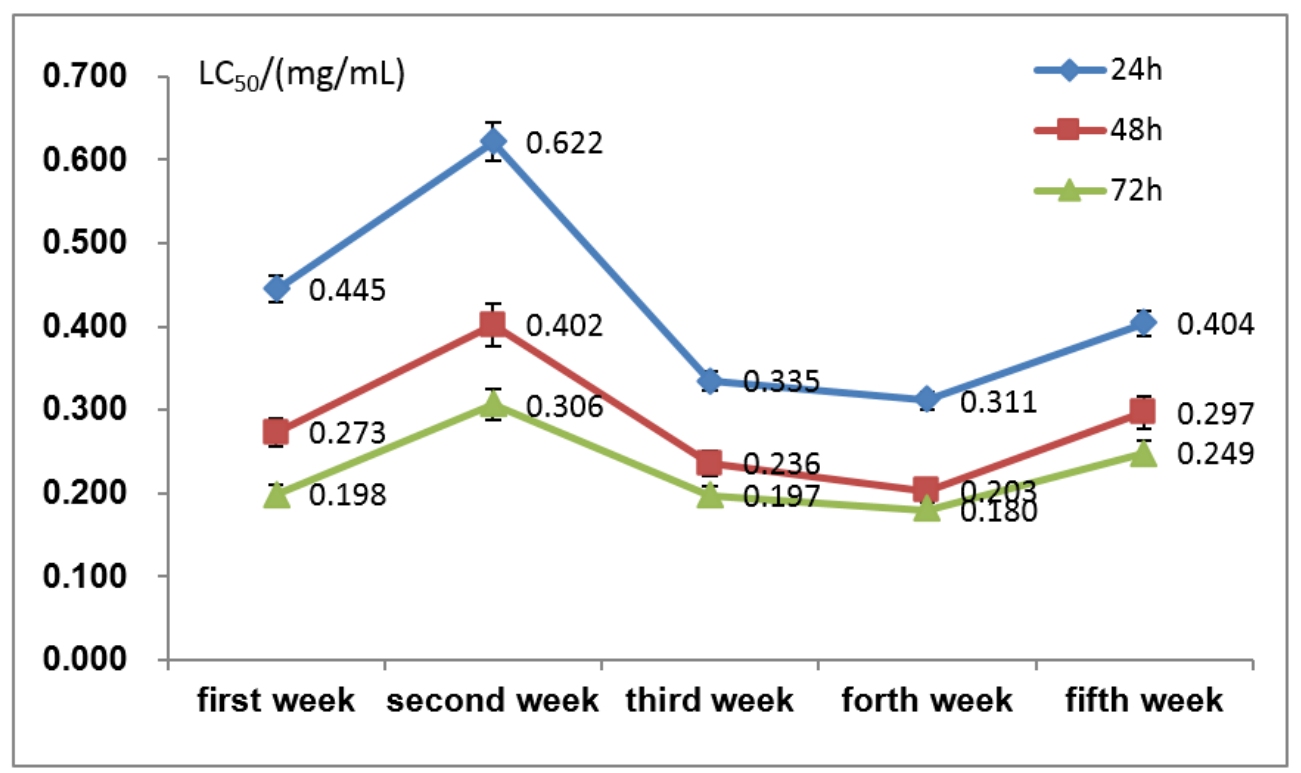

Fig. 7. $L_{50}$ values of flue-cured tobacco on the Bactrocera dorsalis at different time periods

This data provides a feasible idea for the recycling of discarded tobacco leaves and the development of environmentally friendly plant insecticides. However, how to deal with the waste residue after the extraction of the tobacco leaves is still a problem. The waste residue may be used as fertilizer or further extraction for other active substances and so on, which was worth studying further. 


\section{CONCLUSIONS}

1. In this work, the insecticidal activities of three tobacco leaf (flue-cured tobacco, burley tobacco, and sun-cured yellow tobacco) extracts were investigated. The crude extracts were obtained via solvent extraction, and the yield was as follows: sun-cured yellow tobacco was greater than flue-cured tobacco, which was greater than burley tobacco. The insecticidal substances in the crude extract were alkaloids, and the crude extract was analyzed via HPLC-MS/MS to quantify the main alkaloids (nicotine, anatabine, nornicotine, and anabasine). The total contents of the four alkaloids in the three extracts were as follows: flue-cured tobacco $(62.1 \%)$ was greater than sun-cured yellow tobacco $(58.2 \%)$, which was greater than burley tobacco $(50.7 \%)$.

2. The potential insecticidal activity of the extracts against Bactrocera dorsalis were investigated using the stomach poisoning method. It was found that sex had no significant effect on the activity. Burley tobacco, which was rich in minor alkaloids, had the best bioactivity of the three extracts after $24 \mathrm{~h}$ from administration.

3. The minor alkaloids showed better bioactivity than nicotine over a short period of time. As such, the authors speculated that this might be due to the multiple modes of action of the minor alkaloids. This study also tested the toxicity of flue-cured tobacco on Bactrocera dorsalis at different time periods (1 week, 2 weeks, 3 weeks, 4 weeks, and 5 weeks) after eclosion. It was found that the vitality of Bactrocera dorsalis during the second week was the worst, and the vitality of Bactrocera dorsalis in the fourth week was the best. The $\mathrm{LC}_{50}$ values are useful in choosing an appropriate concentration of the extract for killing Bactrocera dorsalis during a certain time period, especially in the initial occurrence of pest infestation.

\section{ACKNOWLEDGEMENTS}

This work was financially supported by the research program on the relationship between nicotine and Alzheimer's disease (Grant No. 110201801035(JY-09)).

\section{REFERENCES CITED}

Ali, M. W., Zheng, W. P., Sohail, S., Li, Q. M., Zheng, W. W., and Zhang, H. Y. (2017).

"A genetically enhanced sterile insect technique against the fruit fly, Bactrocera dorsalis (Hendel) by feeding adult double-stranded RNAs," Scientific Reports 7, 111. DOI: $10.1038 / \mathrm{s} 41598-017-04431-\mathrm{z}$

Ant, T., Koukidou, M., Rempoulakis, P., Gong, H.-F., Economopoulos, A., Vontas, J., and Alphey, L. (2012). "Control of the olive fruit fly using genetics-enhanced sterile insect technique," BMC Biology 10, 1-8.

Armstrong, D. W., Wang, X., Lee, J.-T., and Liu, Y.-S. (1999). "Enantiomeric composition of nornicotine, anatabine, and anabasine in tobacco," Chirality 11(1), 8284. DOI: 10.1002/(SICI)1520-636X(1999)11:1<82::AID-CHIR14>3.0.CO;2-C 
Balandrin, M. F., Klocke, J. A., Wurtele, E. S., and Bollinger, W. H. (1985). "Natural plant chemicals: Sources of industrial and medicinal materials," Science 228(4704), 1154-1160. DOI: $10.1126 /$ science.3890182

Booker, C. J., Bedmutha, R., Vogel, T., Gloor, A., Xu, R., Ferrante, L., Yeung, K. K.-C., Scott, I. M., Conn, K. L., Berruti, F., et al. (2010). "Experimental investigations into the insecticidal, fungicidal, and bactericidal properties of pyrolysis bio-oil from tobacco leaves using a fluidized bed pilot plant," Industrial \& Engineering Chemistry Research 49(20), 10074-10079. DOI: 10.1021/ie100329z

Clarke, A. R., Armstrong, K. F., Carmichael, A. E., Milne, J. R., Raghu, S., Roderick, G. K., and Yeates, D. K. (2005). "Invasive phytophagous pests arising through a recent tropical evolutionary radiation: The Bactrocera dorsalis complex of fruit flies," Annual Review of Entomology 50, 293-319. DOI: 10.1146/annurev.ento.50.071803.130428

Dogan, M., Emsen, B., Aasim, M., and Yildirim, E. (2017). "Ceratophyllum demersum L. extract as a botanical insecticide for controlling the maize weevil, Sitophilus zeamais Motschulsky (Coleoptera: Curculionidae)," Egyptian Journal of Biological Pest Control 27(1), 11-15.

Famele, M., Palmisani, J., Ferranti, C., Abenavoli, C., Palleschi, L., Mancinelli, R., Fidente, R. M., Gennaro, G., and Draisci, R. (2017). "Liquid chromatography with tandem mass spectrometry method for the determination of nicotine and minor tobacco alkaloids in electronic cigarette refill liquids and second-hand generated aerosol," Journal of Separation Science 40(5), 1049-1056. DOI: 10.1002/jssc. 201601076

Hu, R.-S., Wang, J., Li, H., Ni, H., Chen, Y.-F., Zhang, Y.-W., Xiang, S.-P., and Li, H.H. (2015). "Simultaneous extraction of nicotine and solanesol from waste tobacco materials by the column chromatographic extraction method and their separation and purification," Separation and Purification Technology 146, 1-7. DOI: 10.1016/j.seppur.2015.03.016

Kim, S., Jung, M., Song, Y.-J., Kang, S. C., Kim, B., Choi, I.-J., Kim, H. G., and Lee, D.H. (2017). "Evaluating the potential of the extract of Perilla sp as a natural insecticide for Bemisia tabaci (Hemiptera: Aleyrodidae) on sweet peppers," Entomological Research 47(3), 208-216. DOI: 10.1111/1748-5967.12211

Kumar, P. M., Kovendan, K., and Murugan, K. (2013). "Integration of botanical and bacterial insecticide against Aedes aegypti and Anopheles stephensi," Parasitology Research 112, 761-771. DOI: 10.1007/s00436-012-3196-z

Li, Q., Dong, X., Zheng, W., and Zhang, H. (2017). "The PLA2 gene mediates the humoral immune responses in Bactroceradorsalis (Hendel)," Developmental \& Comparative Immunology 67, 293-299. DOI: 10.1016/j.dci.2016.09.006

Li, X., Zhang, M., and Zhang, H. (2011). "RNA interference of four genes in adult Bactrocera dorsalis by feeding their dsRNAs," Plos One 6(3), 1-11. DOI: 0.1371/journal.pone.0017788

Li, Y., Pang, T., Shi, J., Lu, X., Deng, J., and Lin, Q. (2015). "Simultaneous determination of alkaloids and their related tobacco-specific nitrosamines in tobacco leaves using LC-MS-MS," Journal of Chromatographic Science 53(10), 1730-1736. DOI: $10.1093 /$ chromsci/bmv082 
Piton, L. P., Turchen, L. M., Butnariu, A. R., and Pereira, M. J. B. (2014). "Natural insecticide based-leaves extract of Piper aduncum (Piperaceae) in the control of stink bug brown soybean," Ciêncica Rural 44(11), 1915-1920. DOI: 10.1590/01038478 cr20131277

Puripattanavong, J., Songkram, C., Lomlim, L., and Amnuaikit, T. (2013). "Development of concentrated emulsion containing nicotiana tabacum extract for use as pesticide," Journal of Applied Pharmaceutical Science 3(11), 16-21. DOI: 10.7324/JAPS.2013.31104

Saunders, J. A., and Blume, D. E. (1981). "Quantitation of major tobacco alkaloids by high-performance liquid chromatography," Journal of Chromatography A 205(1), 147-154. DOI: 10.1016/S0021-9673(00)81822-1

Scott, I. M., Gagnon, N., Lesage, L., Philogene, B. J. R., and Arnason, J. T. (2005). "Efficacy of botanical insecticides from Piper species (Piperaceae) extracts for control of European chafer (Coleoptera: Scarabaeidae )," Journal of Economic Entomology 98(3), 845-855. DOI: 10.1603/0022-0493-98.3.845

Silva, F. R. d., Erdtmann, B., Dalpiaz, T., Nunes, E., Ferraz, A., Martins, T. L. C., Dias, J. F., Rosa, D. P. d., Porawskie, M., Bona, S., et al. (2013). "Genotoxicity of Nicotiana tabacum leaves on Helix aspersa," Genetics and Molecular Biology 36(2), 269-275. DOI: 10.1590/S1415-47572013005000020

Sudan, B. J. L., Brouillard, C., Strehler, C., Strub, H., Sterboul, J., and Sainte-Laudy, J., (1984). "Determination of nicotine in allergenic extracts of tobacco leaf by highperformance liquid chromatography," Journal of Chromatography A 288, 415-422. DOI: $10.1016 / \mathrm{S} 0021-9673(01) 93717-3$

Weymarn, L. B. v., Thomson, N. M., Donny, E. C., Hatsukami, D. K., and Murphy, S. E. (2016). "Quantitation of the minor tobacco alkaloids nornicotine, anatabine, and anabasine in smokers' urine by high throughput liquid chromatography-mass spectrometry," Chemical Research in Toxicology 29(3), 390-397. DOI:

10.1021/acs.chemrestox.5b00521

Xu, C., Zhao, S., Li, M., Dai, Y., Tan, L., and Liu, Y. (2016). "Chemical composition, antimicrobial and antioxidant activities of essential oil from flue-cured tobacco flower bud," Biotechnology \& Biotechnological Equipment 30(5), 1026-1030. DOI: 10.1080/13102818.2016.1195240

Xu, X., Iba, M. M., and Weisel, C. P. (2004). "Simultaneous and sensitive measurement of anabasine, nicotine, and nicotine metabolites in human urine by liquid chromatography-tandem mass spectrometry," Clinical Chemistry 50(12), 2323-2330. DOI: $10.1373 /$ clinchem.2004.038489

Yuan, C., Kosewick, J., and Wang, S. (2013). "A simple, fast, and sensitive method for the measurement of serum nicotine, cotinine, and nornicotine by LC-MS/MS," Journal of Separation Science 36(15), 2394-2400. DOI: 10.1002/jssc. 201300220

Zagorevski, D. V., and Loughmiller-Newman, J. A. (2012). "The detection of nicotine in a Late Mayan period flask by gas chromatography and liquid chromatography mass spectrometry methods," Rapid Communications in Mass Spectrometry 26(4), 403411. DOI: $10.1002 / \mathrm{rcm} .5339$

Zammit, M., Shoemake, C., Attard, E., and Azzopardi, L. M. (2014). "The effects of anabasine and the alkaloid extract of nicotiana glauca on Lepidopterous larvae," International Journal of Biology 6(3), 46-53. DOI: 10.5539/ijb.v6n3p46 
Zhang, X., Gao, H., Zhang, L., Liu, D., and Ye, X. (2012). "Extraction of essential oil from discarded tobacco leaves by solvent extraction and steam distillation, and identification of its chemical composition," Industrial Crops and Products 39, 162169. DOI: $10.1016 /$ j.indcrop.2012.02.029

Article submitted: November 11, 2021; Peer review completed: January 9, 2022; Revised version received and accepted: January 19, 2022; Published: January 25, 2022.

DOI: $10.15376 /$ biores.17.1.1764-1780 